\title{
Metabolic pathways of decabromodiphenyl ether (BDE209) in rainbow trout (Oncorhynchus mykiss) via intraperitoneal injection
}

\author{
Chenglian Feng ${ }^{a, b}$, Yiping $\mathrm{Xu}^{b, *}$, Jinmiao $\mathrm{Zha}^{b}$, Jian $\mathrm{Li}^{c}$, Fengchang $\mathrm{Wu}^{a}$, \\ Zijian Wang ${ }^{b}$ \\ a State Key Laboratory of Environmental Criteria and Risk Assessment, Chinese Research Academy of \\ Environmental Sciences, Beijing 100012, China \\ b State Key Laboratory of Environmental Aquatic Chemistry, Research Center for Eco-Environmental Sciences, \\ Chinese Academy of Sciences, Beijing 100085, China \\ c Engineering research center of ground water pollution control and remediation, Beijing Normal university, Beijing \\ 100875, China
}

\section{A R T I C L E I N F O}

\section{Article history:}

Received 3 September 2014

Received in revised form

5 January 2015

Accepted 10 January 2015

Available online 20 January 2015

\section{Keywords:}

Decabromodiphenyl ether (BDE209)

Rainbow trout (Oncorhynchus mykiss)

Metabolic pathways

OH-BDEs

MeO-BDEs

\begin{abstract}
A B S T R A C T
Decabromodiphenyl ether (BDE209) was of great concern due to its biotransformation in different organisms. However, most studies devoted to the metabolic intermediates of BDE209, less has been done on the metabolic pathways in vivo, especially on the relationships among debrominated-BDEs, OH-BDEs and MeO-BDEs. In this study, the metabolic pathways and intermediates of BDE209 in rainbow trout (Oncorhynchus mykiss) were investigated, and the time-dependent transformations of the metabolites were also examined. The primary debrominated metabolites were BDE47, 49, 99, 197, 207; the main MeO-BDEs were MeO-BDE47, MeO-BDE68 and MeO-BDE100; OH-BDEs were primarily composed of OH-BDE28 and $\mathrm{OH}-\mathrm{BDE} 42$. From the time-dependent and dose-effect relationships, the debromination should be followed by hydroxylation, and then by methoxylation. The increasing in body burden of MeO-BDEs corresponded to the decreasing of OH-BDEs, which could indirectly prove the inter-conversion between $\mathrm{OH}-\mathrm{BDEs}$ and $\mathrm{MeO}-\mathrm{BDEs}$. This study would motivate the future research of toxicological mechanisms of BDEs.
\end{abstract}

(c) 2015 Elsevier B.V. All rights reserved.

\section{Introduction}

Polybrominated diphenyl ethers (PBDEs) are additive flame retardants that are applied in a variety of consumer products, such as plastics and electronic castings. PBDEs can accumulate in various species, especially in fish, and exposure to some PBDE congeners is associated with health problems such as reproductive and developmental effects, neurobehavioral toxicity and thyroid hormone disruption (Dingemans et al., 2011; Costa et al., 2014; Guyot et al., 2014; Buratovic et al., 2014). Decabromodiphenyl ether (BDE209), which is the principal component of commercial PBDEs, comprises approximately $80 \%$ of the world market demand for PBDEs (de Wit, 2002). BDE209 has unique physicochemical properties, such as extremely low water solubility, large molecular size and very

\footnotetext{
* Corresponding author at: Tel./fax: +86 1062849197.

E-mail addresses: ypxu@rcees.ac.cn, yiping79@gmail.com (Y. Xu).
} 
low bioavailability. Therefore, it is characterized as an environmentally stable and inert product that is hard to degrade in the environment. However, elevated concentrations of BDE209 have been detected in different organisms and environmental media (Van den Steen et al., 2007; Crosse et al., 2012; Wang et al., 2014; Nelson et al., 2015). Previous studies have shown that BDE209 could accumulate in various species, especially in fish (Darnerud et al., 2001).

Many studies have shown that the toxicity of BDE209 itself is relatively lower, while the toxicity might be due to the metabolites, such as hydroxylated BDEs (OH-BDEs) and methoxylated brominated diphenyl ethers (MeO-BDEs). For example, it is reported that OH-BDEs have thyroxine-like and estrogen-like chemical structures that can bind competitively with transthyretin (TTR), a transport protein of thyroid hormones (Meerts et al., 2001). The competitive binding of $\mathrm{OH}-$ BDE to TTR is considered to be potentially responsible for the disruption of thyroid homeostasis (Li et al., 2010). However, whether BDE209 could be metabolized to toxic intermediates and which metabolic pathways that govern the metabolism in biota have not been clearly addressed. Some toxicological studies have shown that lower brominated diphenyl ethers, which might be a metabolite of BDE209 in biota, are more toxic than higher brominated diphenyl ether (Hooper and McDonald, 2000, Xie et al., 2014). It has also been suggested that deiodinase enzymes play a role in the debromination of BDEs in fish owing to the structural similarity of BDEs to thyroid hormones (Stapleton et al., 2004a; Stapleton et al., 2006). A preliminary study revealed slow but measurable uptake of BDE209 via dietary exposure, with several lower brominated diphenyl ether metabolites being detected in rainbow trout (Kierkegaard et al., 1999). Several published papers have demonstrated the biotic debromination of BDE209 in fish (Roberts et al., 2011). In addition to the debrominated diphenyl ether metabolites, MeO-BDEs and hydroxylated metabolites were also detected in many species (Mörck et al., 2003; Valters et al., 2005; Sun et al., 2013, Wen et al., 2015). However, the majority of research on the occurrence of $\mathrm{MeO}-\mathrm{BDEs}$ and $\mathrm{OH}-$ BDEs in biota samples has attributed its presence to natural biogenetic formation. For example, MeO-BDEs and OH-BDEs were believed to be produced by marine sponges and algae (Teuten et al., 2005), but only limited studies have investigated the metabolism of these compounds from parent BDEs (Malmvärn et al., 2005; Marsh et al., 2006; Wan et al., 2010; Wang et al., 2012). Basically, previous studies of BDE metabolism indicated that metabolism of BDEs in humans and other mammals typically occurred via oxidative pathways, producing OH-BDEs and brominated phenols (Chen et al., 2006). Nevertheless, there was no direct evidence that could prove that exposure to BDEs would undergo oxidative process in fish, leading to the oxidative metabolites of BDEs. Rather, studies about BDEs metabolism in fish mainly focused on the reductive process, with debrominated BDEs being produced (Stapleton et al., 2004b; Stapleton et al., 2004a). Moreover, although the different kinds of BDE209 metabolites were reported, little was known about the metabolic pathway of BDE209 in organisms. The majority of those studies about BDE209 metabolism mainly elaborated the metabolites, including their concentration levels, tissue distribution characteristics and specific congener types. It was still not clear whether its metabolites, e.g., OH-BDEs and MeO-BDEs, could be formed through metabolism in fish in vivo when exposed to environmentally relevant concentrations of parent BDE209.

The present study was conducted (i) to propose the specific metabolic pathways of BDE209 in rainbow trout based on the distribution profiles of its metabolites; (ii) to present the time sequences of BDE209 metabolites; and (iii) to investigate the inter-conversion relationship of OH-BDEs and MeO-BDEs in vivo during the exposure experiment.

\section{Materials and methods}

\subsection{Standards and reagents}

Dichloromethane (DCM), hexane and acetone, which were used for extraction and clean up of the extract, were HPLC grade purchased from Mallinckrodt Baker Inc. (USA). BDE209 used for the exposure experiment were kindly provided by the Dalian Institute of Chemical Physics (DICP), Chinese Academy of Sciences (CAS), China. BDE and MeO-BDE standards were purchased from Wellington Laboratories (Ontario, Canada). BDE mixture standards included BDE209 and 26 potential debrominated BDE congeners (BDE3, 7, 15, 17, 28, $47,49,66,71,77,85,99,100,119,126,138,153,154,156$, 183, 184, 191, 196, 197, 206, 207). MeO-BDE standards were purchased from Wellington Laboratories (Ontario, Canada), including eight tetra- to penta- congeners. OH-BDE standards were obtained from AccuStandard ${ }^{\circledR}$, Inc. (USA), containing eight di- to penta- congeners. ${ }^{13} \mathrm{C}$-labeled $2,2^{\prime}, 4,4^{\prime}$-tetrabromo6-methoxy diphenyl ether (6-MeO-BDE47) and ${ }^{13} \mathrm{C}$-labeled $2,2^{\prime}, 4,4^{\prime}, 6$-pentabromo- $6^{\prime}$-methoxy diphenyl ether (6'-MeOBDE100) were used as recovery surrogates for MeO-BDE congeners. ${ }^{13} \mathrm{C}$-labeled-2,2',4,4' -tetrabromo-6-hydroxy diphenyl ether (6-OH-BDE47) and ${ }^{13} \mathrm{C}$-labeled-2,2',4,4',6-pentabromo$6^{\prime}$-hydroxy diphenyl ether $\left(6^{\prime}-\mathrm{OH}-\mathrm{BDE} 100\right)$ were used as recovery surrogates for $\mathrm{OH}-\mathrm{BDE}$ compounds. ${ }^{13} \mathrm{C}$-labeled $2,2^{\prime}, 3,4,4^{\prime}, 5^{\prime}$-hexabromodiphenyl ether $\left({ }^{13} \mathrm{C}\right.$-BDE138) was used as an internal standard for $\mathrm{MeO}-\mathrm{BDE}$ determination during GC/MS analysis.

\subsection{Experimental design}

Juvenile rainbow trout (about 4 months old), approximately $20 \mathrm{~cm}$ in length and $100 \mathrm{~g}$ in weight, were purchased from a local fish farm. Fish were randomly stocked in $250 \mathrm{~L}$ glass tanks that included control and treatment groups. These fish were maintained in aerated de-chlorinated tap water (using an activated carbon filter) at a constant temperature $\left(15 \pm 2^{\circ} \mathrm{C}\right)$, under a $16 \mathrm{~h}: 8 \mathrm{~h}$ (light: dark) photoperiod, which was close to their optimal temperature range in the natural environment. Fish were acclimated for one week prior to the beginning of the experiment.

BDE209 was dissolved in corn oil to prepare a stock solution with a concentration of $0.25 \mathrm{~g} / \mathrm{L}$. Intraperitoneal injection was carried out for fish exposure. The fish were weighed before injection to determine the volume of dosage per gram body mass of each fish. The intraperitoneal injection process was listed in detail as follows: for the treatment groups, BDE209 was injected with injection syringe. The needle of the syringe 
was inserted along the ventral fin of the fish toward the fish head forward. The angle between the needle and the fish was about 45-60 degree, with the injection depth being $0.5 \mathrm{~cm}$ around. Then, the liquid stock solution was slowly injected into fish. For the control groups, the same injection way was used, only the stock solution was replaced with the same amount of corn oil.

The time-effect experiment and dose-response experiment were conducted separately. Each concentration gradient corresponded to three fish tanks. For the time-effect experiment, fish were injected with $40 \mu \mathrm{L}$ and $200 \mu \mathrm{L}$ of BDE209 stock solution, making the initial exposure concentrations in fish being of 100 and $500 \mathrm{ng} / \mathrm{g}$ (nominal concentration) fresh body weight, respectively. In order to observe the time trend of the BDE209 metabolites, one fish from each tank was sampled on days 1, 2, 4, 7, 14, 21 and 28, and three fish samples would be collected at each sampling procedure. For the dose-response experiment, fish were injected with $20 \mu \mathrm{L}, 40 \mu \mathrm{L}, 80 \mu \mathrm{L}, 200 \mu \mathrm{L}$ and $400 \mu \mathrm{L}$ of BDE209 stock solution, making the initial exposure concentrations in fish being of 50,100, 200, 500 and $1000 \mathrm{ng} / \mathrm{g}$ (nominal concentration) fresh body weight, respectively. The whole exposure time was for 21 days. After $21 \mathrm{~d}$ of exposure, one fish from each tank was sampled. Therefore, there would be three parallel fish samples for each gradient concentration. Throughout the whole experimental period, fish were daily fed commercial dry fish food (Tetra Pond Sticks, Germany). Test solutions were maintained by daily renewal of $90 \%$ of the test solution.

\subsection{Sampling}

To avoid contamination from the gastrointestinal tract, fish were starved for $24-48 \mathrm{~h}$ before sampling. Fish were sacrificed by a blow to the head, after which their mass and length were recorded and blood samples were taken directly from the caudal aorta. Blood was collected into a centrifuge tube containing sodium heparin as an anticoagulant. The blood samples were then immediately separated from the plasma and red blood cells by centrifugation at $4{ }^{\circ} \mathrm{C}$, after which they were stored at $-80^{\circ} \mathrm{C}$ until analysis. The viscera of each fish were dissected, and the liver and kidney were separated and weighed. The remaining fish carcass, liver and kidneys were stored at $-80^{\circ} \mathrm{C}$ until analysis.

\subsection{Sample pretreatment}

The liver and kidney samples were extracted and cleaned up as described in our previous study (Feng et al., 2010). Briefly, freeze drying fish liver and kidney samples were homogenized in a stainless steel blender. Approximately $2 \mathrm{~g}$ of dried fish samples were then mixed with $4 \mathrm{~g}$ of anhydrous sodium sulfate that had been cleaned with DCM and activated at $140^{\circ} \mathrm{C}$ for $24 \mathrm{~h}$ in advance. After being spiked with surrogate standards, the samples were extracted with $100 \mathrm{~mL}$ of DCM/acetone (1:1) for $24 \mathrm{~h}$ in a Soxhlet extraction system. The sample extracts were then concentrated with a rotary evaporator and transferred to a glass bottle with $6 \mathrm{~mL}$ of hexane. The phenolic compounds in the extract were subsequently separated in half and the lipid contents were removed by gel permeation chromatography. The residual extracts were then treated with concentrated sulfuric acid to remove the bulk of the lipids, after which the samples were cleaned on a column containing (from top to bottom) $4 \mathrm{~g}$ anhydrous sodium sulfate, $10 \mathrm{~g}$ of silica gel impregnated with sulfuric acid (30\%) and $2 \mathrm{~g}$ active silica gel. Hexane $(30 \mathrm{~mL})$ was used for elution. The eluted solution was loaded onto a column containing $4 \mathrm{~g}$ anhydrous sodium sulfate and $8 \mathrm{~g}$ acid alumina, after which the column was eluted with $30 \mathrm{~mL}$ hexane/DCM (7:3) that was collected and concentrated under gentle nitrogen evaporation at room temperature. The sample was then reconstituted in $100 \mu \mathrm{L}$ hexane containing ${ }^{13} \mathrm{C}$-labeled BDE138 at $500 \mu \mathrm{g} / \mathrm{L}$ prior to GC-MS analysis.

The pretreatment method of fish plasma samples resembled the previous methods (Qiu et al., 2007). Rather, in order to accommodate the smaller plasma samples in the present study, part of the methods were slightly modified. Briefly, we transferred each sample to a centrifuge tube. After the surrogate standards were added, each sample was denatured with $1 \mathrm{~mL}$ of hydrochloric acid $(6 \mathrm{M})$ and $6 \mathrm{~mL}$ of 2-propanol. The samples were then extracted with $6 \mathrm{~mL}$ of hexane: methyl tert-butyl ether (MTBE) (1:1, V/V) three times by shaking the tube for $>5$ min each time. Then the neutral and phenolic compounds in the extract were separated by partitioning between hexane and potassium hydroxide $(0.5 \mathrm{M}$ in $50 \%$ ethanol). The organic phase was then extracted with $3 \mathrm{~mL}$ of hexane three times, after which the organic phases were combined and acidified with $2 \mathrm{~mL}$ of hydrochloric acid $(0.5 \mathrm{M})$. The phenolic compounds were then extracted three times with hexane: MTBE (9:1, V/V), after which the neural fraction was cleaned up by using a column containing (from top to bottom) $8 \mathrm{~g}$ of anhydrous sodium sulfate, $8 \mathrm{~g}$ of silica gel impregnated with sulfuric acid (30\%), $1 \mathrm{~g}$ of active silica gel and $8 \mathrm{~g}$ of acid alumina. Hexane $(10 \mathrm{~mL})$ was first used for elution, and the elution was retarded. The column was then eluted with $20 \mathrm{~mL}$ of hexane/DCM (7:3), after which the eluate was collected and concentrated under gentle nitrogen evaporation at room temperature. Next, the sample was reconstituted in $100 \mu \mathrm{L}$ of hexane containing ${ }^{13} \mathrm{C}$ labeled BDE138 at $500 \mu \mathrm{g} / \mathrm{L}$ and cleaned up by gel permeation chromatography (GPC) to remove the lipids. Finally, the samples were filtered with $0.2 \mu \mathrm{m}$ film prior to UPLC-MS-MS analysis.

\subsection{Instrumental analysis}

Extracts from rainbow trout tissues were analyzed by GC/MS to identify and quantify the neutral fraction of BDE209 metabolites, including debrominated and methoxylated BDEs. BDEs and $\mathrm{MeO}-\mathrm{BDEs}$ were analyzed using an Agilent 6890 gas chromatograph (GC) connected to an Agilent 5975 network mass spectrometer (MS) as previously described (Feng et al., 2010). Briefly, to determine the mono- to hexa-BDE and MeO-BDEs, a DB- $5 \mathrm{~ms}$ capillary column $(30 \mathrm{~m} \times 0.25 \mathrm{~mm}$ i.d. $\times 0.25 \mu \mathrm{m}$ film thickness) was used. For determination of the hepta- to decaBDEs, a DB-5ms capillary column $(15 \mathrm{~m} \times 0.25 \mathrm{~mm}$ i.d. $\times 0.1 \mu \mathrm{m}$ film thickness) was used. Electron ionization (EI) and electroncapture negative ionization (ECNI) were both used to quantify the fragment ions.

$\mathrm{OH}-\mathrm{BDEs}$ were analyzed using an Acquity ultra performance liquid chromatograph (UPLC) (Waters, USA) equipped with a Quattro Premier XE tandem mass spectrometer 
(MS-MS). An Acquity UPLC ${ }^{\circledR}$ BEH $\mathrm{C}_{18}$ column $(2.1 \mathrm{~mm}$ i.d. $\times 50 \mathrm{~mm}$ I. D. $\times 1.7 \mu \mathrm{m}$ film thickness) was used for UPLC separation. The column oven was kept at $35^{\circ} \mathrm{C}$, the flow rate was $0.35 \mathrm{~mL} / \mathrm{min}$, and the injection volume was $10 \mu \mathrm{L}$. Solvent A (water) and B (acetonitrile) were used as the mobile phase under the following linear gradient conditions: initial, A 50\%, B 50\%; at $2 \mathrm{~min}, \mathrm{~A} 30 \%$, B $70 \%$; at $5 \mathrm{~min}$, A $20 \%$, B $80 \%$; at $5.2 \mathrm{~min}$ A $50 \%$, B $50 \%$, with a hold for $2 \mathrm{~min}$. The mass spectrometer was operated in negative mode electro-spray ionization (ESI-) multiple reaction monitoring (MRM) mode under the following conditions: capillary voltage, $3 \mathrm{KV}$; cone gas flow, $50 \mathrm{~L} / \mathrm{h}$; desolvation gas temperature, $350^{\circ} \mathrm{C}$; desolvation gas flow, $650 \mathrm{~L} / \mathrm{h}$. In addition, the MRM monitor ions and cone and collision energies were optimized for each compound. The limit of detection (LOD) for all of the OH-BDEs congeners ranged from 0.15 to $0.78 \mathrm{ng} / \mathrm{g}$. Moreover, the recovery of surrogate standards in spiked blanks ranged from $85.9 \%$ to $100.8 \%$, which was in agreement with the EPA standard.

\subsection{Statistical analysis}

Statistical analysis of the obtained results was performed using SPSS 13.0 for Windows. Spearman rank correlation was used to examine the strength of associations between parameters. Kruskal-Wallis nonparametric tests were used to compare the differences among groups. Analysis of variance (ANOVA) was performed on all experimental data. Probability values less than 0.05 were considered to be statistically significant.

\section{Results}

The fish body mass, liver mass and hepatic somatic index (HSI, mass of liver/body mass $\times 100 \%$ ) of the juvenile rainbow trout were measured throughout the exposure experiment. Comparison of these factors between the control and treated fish revealed no significant differences (data not shown). Debrominated BDEs, MeO-BDEs and OH-BDEs were not observed in the control group and fish food, neither in the stock BDE209 solution. Therefore, the debrominated BDE, MeO-BDEs and $\mathrm{OH}-\mathrm{BDEs}$ detected in rainbow trout in the treatment groups were recognized as BDE209 metabolites. Hydroxylation and methoxylation metabolic pathways and the sequences of the metabolites of BDE209 were proposed.

\subsection{Types and levels of BDE209 metabolites}

Three types of BDE209 metabolites (debrominated BDEs, $\mathrm{MeO}-\mathrm{BDEs}$ and $\mathrm{OH}-\mathrm{BDEs}$ ) were identified in the exposure groups. A total of $19 \mathrm{BDE}$ congeners were detected, including one mono-BDE (BDE3), two di-BDEs (BDE15, 17), one tri-BDE (BDE28), five tetra-BDEs (BDE47, 49, 66, 71, 77), five pentaBDEs (BDE85, 99, 100, 119, 126), one hepta-BDE (BDE183), one octa-BDE (BDE197), two nona-BDEs (BDE206, 207), and deca$\mathrm{BDE}$ (BDE209). Among these, the predominant congeners were BDE47, BDE49, BDE99, BDE197 and BDE207. Additionally, seven MeO-BDEs were detected, 5-MeO-BDE47, 6-MeO-BDE47, 4'MeO-BDE49, 2'-MeO-BDE68, 5'-MeO-BDE100, 4'-MeO-BDE101 and $4^{\prime}-\mathrm{MeO}-\mathrm{BDE} 103$. Among these, the predominant congener

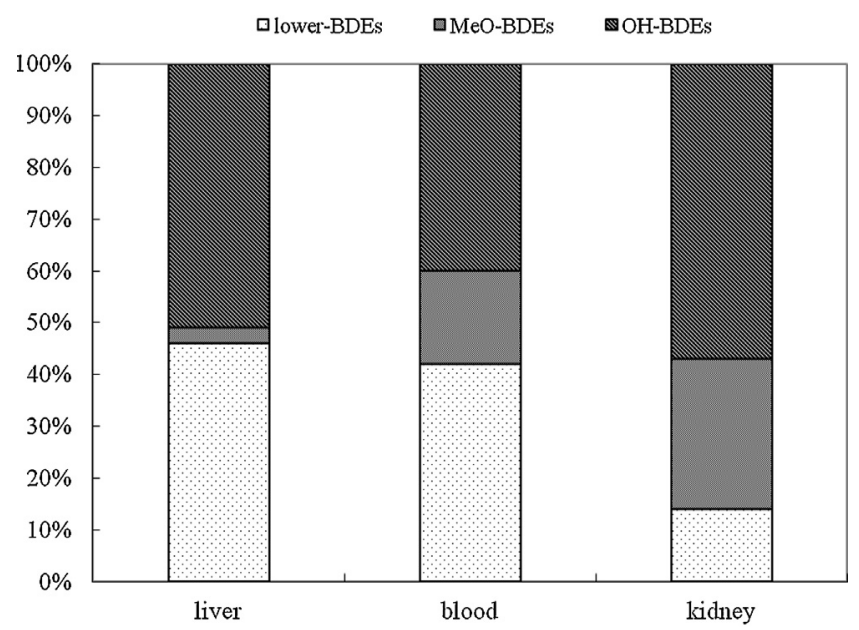

Fig. 1 - Percentage contributions of BDEs, MeO-BDEs and OH-BDEs in liver, blood and kidney in rainbow trout after 28-day exposure to BDE209 at the dose of $100 \mathrm{ng} / \mathrm{g}$ in the time-effect experiment.

was 5-MeO-BDE47, followed by 4'-MeO-BDE49. Only two of the eight OH-BDEs were detected, $3^{\prime}-\mathrm{OH}-\mathrm{BDE} 28$ and $4-\mathrm{OH}-$ $\mathrm{BDE} 42$. In order to investigate the distribution characteristics of BDE209 metabolites in different tissue (organs), the composition proportion of the three kinds of metabolites were also analyzed and calculated at the end of the time-effect experiment at the dose of $100 \mathrm{ng} / \mathrm{g}$ (day 28). It could be easily found in Fig. 1 that after 28-day exposure, significant tissue distribution differences were observed among the three types of metabolites. In liver, the predominant fractions were $\mathrm{OH}-\mathrm{BDEs}$ and debrominated BDEs, with MeO-BDEs accounting for approximately $3 \%$ of the total. The metabolite distribution in blood presented a similar trend. In kidney, debrominated BDEs were relatively lower, accounting for only $14 \%$ of the total metabolites, while OH-BDEs and MeO-BDEs accounted for 57\% and $29 \%$ of the total metabolites, respectively.

\subsection{Time trend of $\mathrm{OH}-\mathrm{BDEs}$ and $\mathrm{MeO}-\mathrm{BDEs}$ in rainbow trout}

In the time-effect experiment, the time trend of OH-BDEs and MeO-BDE metabolite concentrations were determined. The total amount of $\mathrm{OH}-\mathrm{BDEs}$ and $\mathrm{MeO}-\mathrm{BDEs}$ at the different time points for the initial dose of $500 \mathrm{ng} / \mathrm{g}$ of the fish group was listed in Fig. 2. It could be easily found that there was a different concentration change trend between the two metabolites. Specifically, after exposure to BDE209 for seven days, the total concentration of OH-BDEs began to decrease; while the total concentration of MeO-BDE began to increase, which might imply biotransformation from OH-BDE to MeO-BDEs.

\section{Discussion}

There were tissue distribution differences among species, especially for the debrominated BDEs. For example, in European starlings, no lower brominated BDEs were detected in blood samples, while in the liver, the main congeners 


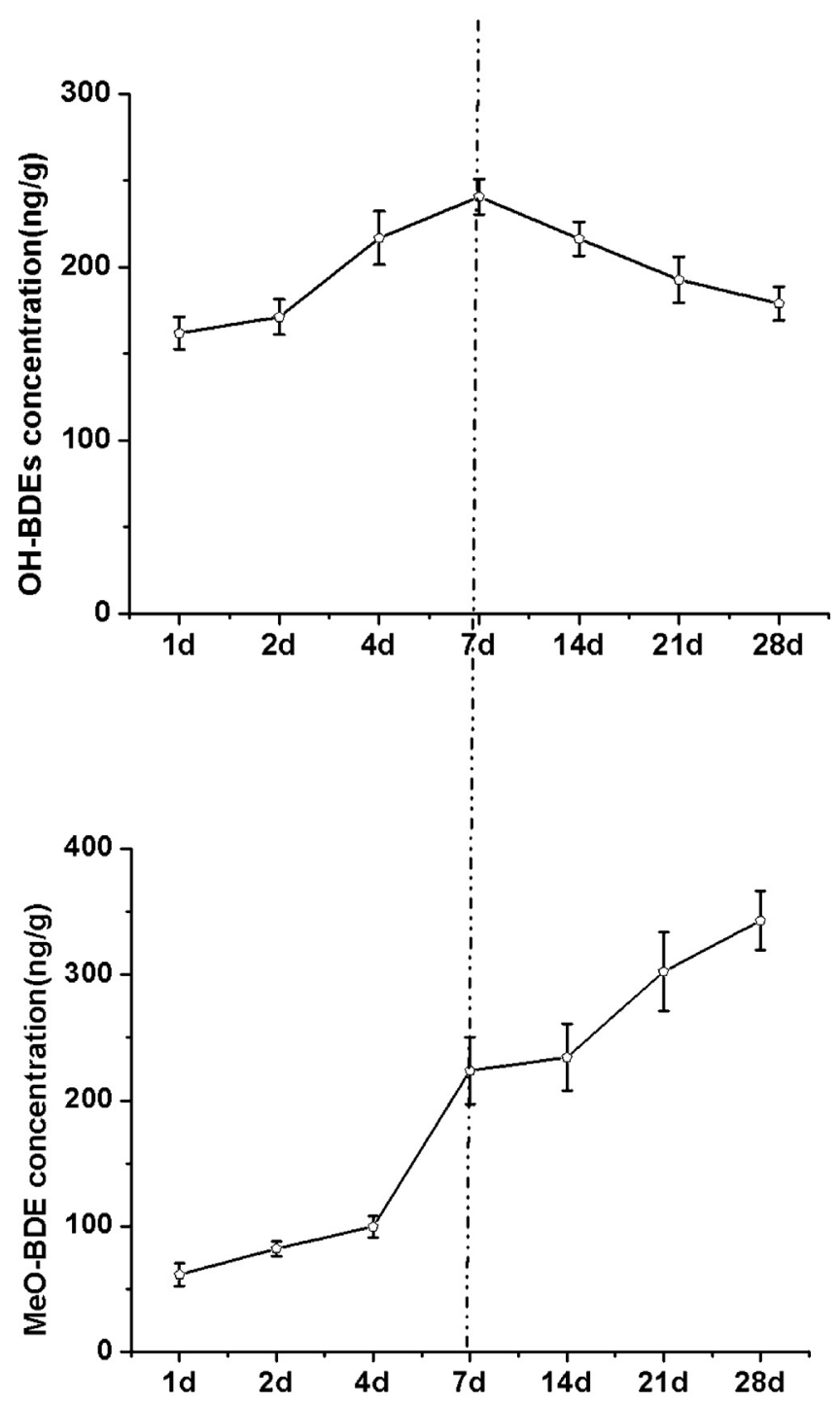

Fig. 2 - Time change trend of total concentration of $\mathrm{OH}-\mathrm{BDEs}$ and MeO-BDEs in liver of the rainbow trout during the whole exposure time $(28 \mathrm{~d})$ at the dose of $500 \mathrm{ng} / \mathrm{g}$ in the time-effect experiment. The dotted line represents the change point of concentration trend.

were BDE207 (24\% of total metabolites), BDE208 (9.2\%) and BDE206 (4.0\%), followed by BDE197 and BDE153 (Van den Steen et al., 2007). In common carp, several hepta- and hexaBDEs (e.g., BDE154 and BDE155) were observed when exposed to BDE209 (Stapleton et al., 2004a). The differences in BDE metabolites between our study and others suggested possible species-specific differences in their metabolic capacities. Such differences might be due to different exposure routes and tested species (Montory and Barra, 2006).

OH-BDEs metabolites were of particular interest because they might elicit a variety of effects on organisms, such as disruption of thyroid hormone homeostasis and neurotoxic effects (Meerts et al., 2001; Harju et al., 2007; Dingemans et al., 2008;). OH-BDEs have been detected in different organisms. For example, OH-BDEs were found at greater concentrations in marine algae, suggesting that they could be formed naturally in marine algae or by their associated microorganisms (Marsh et al., 2004; Malmvärn et al., 2005). Hydroxylation was an important metabolic pathway of PBDEs in animals. It has been shown that OH-BDEs were biotransformation products of PBDEs, which were reported in rat and human cells (Malmberg et al., 2005; Hamers et al., 2008; Stapleton et al., 2009). In the present study, two types of OH-BDEs profiles were observed throughout the experiment, $3^{\prime}-\mathrm{OH}-\mathrm{BDE} 28$ and 4-OH-BDE42, which might be formed through BDE oxidative metabolism. It was once suspected that hydroxylation of PBDEs was mediated by cytochrome P450 enzymes, which could account for direct hydroxylation or hydroxylation via a 1,2-shift. In addition, the 1,2-shift mechanism proceeded via an arene oxide intermediate (Guroff et al., 1967; Jerina and Daly, 1974). Moreover, previous studies suggested that orthosubstituted OH-BDEs were formed from naturally occurring compounds in marine ecosystems (Teuten et al., 2005), while meta- or para-substituted OH-BDEs could originate from the biotransformation of synthetic BDEs (Malmberg et al., 2005; Hamers et al., 2008). Based on this theory, the two OH-BDEs observed in the present study were composed of one metaand one para- substituted hydroxy radicals, which may have been formed through parent BDEs such as BDE47 and BDE28. As mentioned above, BDE47 and BDE28 have been shown to be the debromination products of BDE209. Therefore, the OH-BDE products could be thought as indirect metabolites of BDE209 in rainbow trout. From the results of time-dependent experiment, the debromination process of BDE209 metabolism took place first. Then, the hydroxylation process occurred after the debromination process. The likely pathways of the OH-BDEs formation were displayed in Fig. 3.

Most studies have assumed that MeO-BDEs were solely natural in origin (Handayani et al., 1997; Malmvärn et al., 2008). There was little evidence of the transformation of BDEs or OH$\mathrm{BDEs}$ to $\mathrm{MeO}-\mathrm{BDEs}$ in vivo, although the transformation from $\mathrm{OH}-\mathrm{BDEs}$ to $\mathrm{MeO}-\mathrm{BDE}$ was thought to be possible. When $\mathrm{MeO}-$ BDE was present in freshwater organisms, 2'-MeO-BDE68 and 6-MeO-BDE47 were detected at high concentrations, and were thought to be metabolites of BDEs (Kelly et al., 2008). It was also suggested that naturally occurring $\mathrm{MeO}-\mathrm{BDEs}$ and $\mathrm{OH}-$ BDEs had a preference for the para- position as opposed to the ortho- or meta- position, especially for biotic metabolism (Athanasiadou et al., 2008). In the present study, most MeOBDEs metabolites were found to have a preference for the metaand para- position, such as 4'-MeO-BDE47 and 5'-MeO-BDE100, which might indirectly confirm the theory of the metabolism process from BDEs to MeO-BDEs.

It was of great interest in the origin of $\mathrm{OH}-\mathrm{BDEs}$ and $\mathrm{MeO}-$ BDEs in biotic environmental matrices, whether they could be transformed to each other have not be comprehensively confirmed. OH-BDEs and MeO-BDEs, which were thought to be metabolites of BDEs, have been found in wildlife (Marsh et al., 2004; Verreault et al., 2005; Sun et al., 2013; Wang et al., 2014). Overall, the results of BDE metabolism studies that have been conducted to date suggest that $\mathrm{OH}$-BDEs were formed by hydroxylation of $\mathrm{BDEs}$, and $\mathrm{MeO}-\mathrm{BDEs}$ were then formed by methoxylation of OH-BDEs (Wiseman et al., 2011). It should be noted that our results were supported by those of Wan et al. (Wan et al., 2009, 2010), who observed interconversion of 6 $\mathrm{MeO}-\mathrm{BDE} 47$ and 6-OH-BDE47 in Japanese medaka both in vitro 
<smiles>Brc1ccc(Oc2ccc(Br)cc2Br)c(Br)c1</smiles><smiles>CCOCCOCCOc1ccc(Br)c(Br)c1</smiles>

$+$

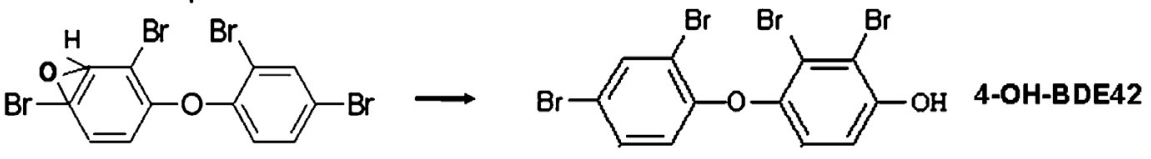<smiles>CCOC(=O)Oc1ccc(Br)c(Oc2ccc(Br)c(Br)c2)c1</smiles>

Fig. 3 - Proposed hydroxylation pathway of BDE47 and BDE28 in rainbow trout after exposure to BDE209. BDE47 and BDE28 were the detected metabolites of BDE209 during the exposure time in rainbow trout.

and in vivo. These similar results confirmed that the transformation from $\mathrm{OH}-\mathrm{BDE}$ to $\mathrm{MeO}-\mathrm{BDEs}$ was a likely pathway. Fig. 4 illustrated the proposed pathway of the formation of MeO-BDEs.

Moreover, dose-response experiment was further conducted to analyze the specific relationship between $\mathrm{OH}-\mathrm{BDEs}$ and MeO-BDEs. The results showed that after 21-day exposure time, there was a significant positive correlation between the total concentration of $\mathrm{OH}-\mathrm{BDEs}$ and $\mathrm{MeO}-\mathrm{BDEs}$ in different fish tissues $(p<0.05)$ (Fig. 5). The different levels of OH-BDEs and MeO-BDEs might also be due to the different in vivo kinetics involved in their elimination. This phenomenon has also<smiles>Brc1ccc(Oc2ccc(Br)cc2Br)c(Br)c1</smiles><smiles>COC(=O)Oc1ccc(Br)cc1Oc1cc(Br)ccc1Br</smiles><smiles>CC(C)(C)Br</smiles><smiles>Oc1cc(Oc2cc(Br)c(Br)cc2Br)c(Br)cc1Br</smiles><smiles>Brc1ccc(Oc2c(Br)cc(Br)cc2Br)c(Br)c1</smiles>

BDE100<smiles>Oc1cc(Br)c(Oc2ccc(Br)cc2Br)cc1Br</smiles><smiles>Oc1cc(Oc2c(Br)cc(Br)cc2Br)c(Br)cc1Br</smiles><smiles>Oc1cc(Oc2ccc(Br)cc2Br)c(Br)cc1Br</smiles><smiles>ICI</smiles><smiles>COc1cc(Oc2ccc(Br)cc2Br)c(Br)cc1Br</smiles><smiles>CCOc1cc(Br)c(Oc2ccc(Br)cc2Br)cc1Br</smiles>

4'-MeO-BDE47<smiles>CC(C)C(=O)OCc1cc(Oc2cc(Br)c(Br)cc2Br)c(Br)cc1Br</smiles>

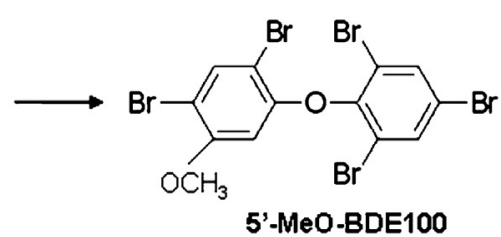

Fig. 4 - Proposed methoxylation pathway of BDE47, BDE49, BDE99 and BDE100 in rainbow trout after exposure to BDE209. BDE47, BDE49, BDE99 and BDE100 were the detected metabolites of BDE209 during the exposure time in rainbow trout. 

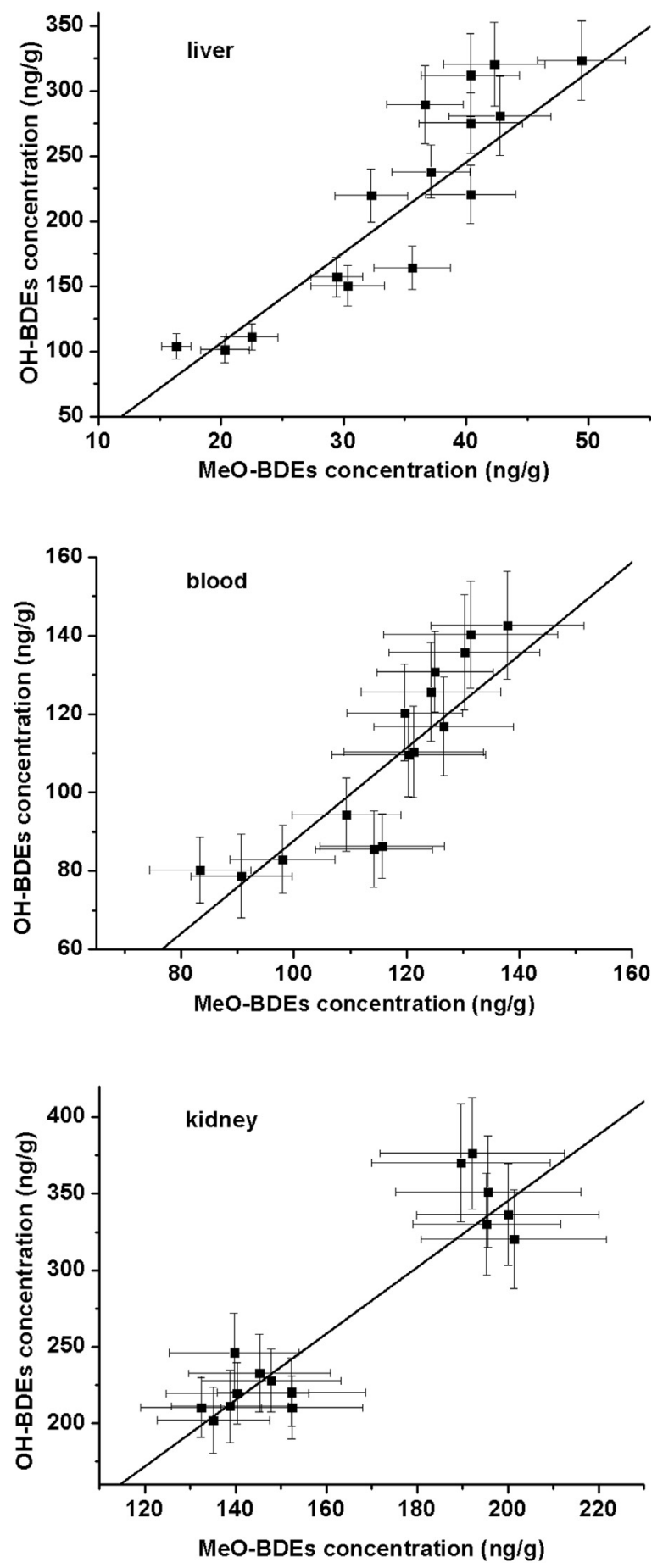

Fig. 5 - Correlation of total concentration of OH-BDEs and MeO-BDEs in liver, blood and kidney after 21-day exposure to BDE209 at the dose gradients of $50 \mathrm{ng} / \mathrm{g}, 100 \mathrm{ng} / \mathrm{g}$, $200 \mathrm{ng} / \mathrm{g}, 500 \mathrm{ng} / \mathrm{g}$ and $1000 \mathrm{ng} / \mathrm{g}(p<0.05)$.

been observed in other brominated flame retardants, such as hexabromocyclododecane (Szabo et al., 2010).

Based on the aforementioned results, the metabolism of BDE209 in rainbow trout could undergo three possible pathways: debromination, hydroxylation and methoxylation. Moreover, the time-effect and dose-effect relationships of these metabolites showed that debromination process of

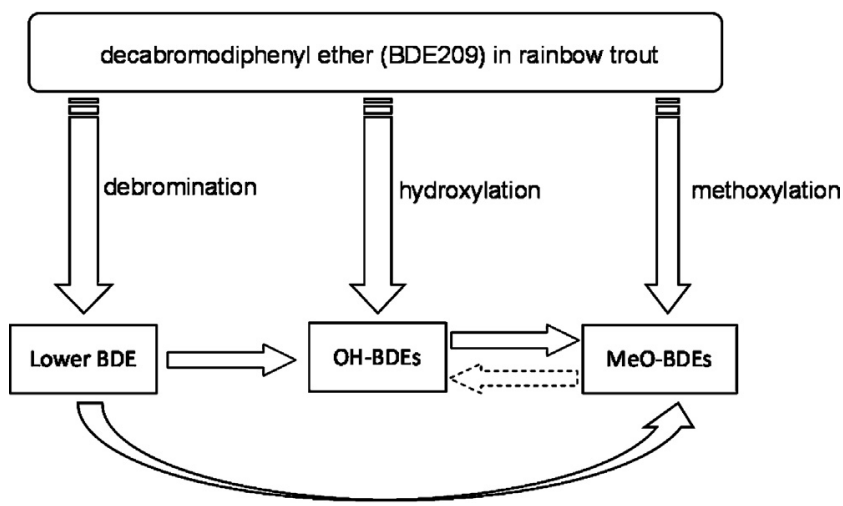

Fig. 6 - Proposed metabolic pathways of BDE209 in rainbow trout. Solid line arrows indicate the proposed pathways; dashed line arrows indicate the potential pathways that have not yet been confirmed in the present study.

BDE209 metabolism first occurred, followed by hydroxylation, and then by methoxylation. In addition, biotransformation from $\mathrm{OH}-\mathrm{BDEs}$ to MeO-BDEs might also occur. However, it was unclear whether an inverse transformation process from $\mathrm{MeO}-\mathrm{BDEs}$ to OH-BDEs occurs; therefore, further investigation through in vivo or in vitro study would be warranted. In addition, a previous in vivo investigation of BDE metabolism using mice suggested another metabolic pathway, cleavage of the diphenyl ether bond (Qiu et al., 2007). A similar pathway was also observed for BDE99 metabolism in an in vitro study using human liver cells, with the formation of 2,4,5-tribromophenol (Stapleton et al., 2009). While in our study, bromophenols were not included in the standards, and were not able to be detected. Thus, we could not provide direct evidence to support this metabolic pathway of BDE209. The overall metabolic pathways in rainbow trout were illustrated in Fig. 6.

\section{Conclusions}

There seemed to be three possible metabolic pathways of BDE209 in rainbow trout after a single intraperitoneal injection, i.e., debromination, hydroxylation, and methoxylation. The tissue distribution of these three metabolites varied significantly, with debrominated BDEs being primarily in liver, MeO-BDEs mainly existing in blood and kidney and OH-BDEs mostly occurring in liver and kidney. The debrominated BDEs might form through direct debromination of BDE209 or the further debromination of lower BDE metabolites. The observed $\mathrm{OH}-\mathrm{BDEs}$ and $\mathrm{MeO}-\mathrm{BDEs}$, which were recognized as biotransformation products of BDE209, had a preference for the metaand para- position over the ortho- position. Furthermore, a significant positive correlation and similar time trend between $\mathrm{OH}-\mathrm{BDEs}$ and MeO-BDEs was also observed, which may indirectly provide evidence of a possible conversion pathway from OH-BDEs to MeO-BDEs. The time-dependent relationship of these metabolites showed that debromination of BDE209 was followed by hydroxylation, and then by methoxylation. Undoubtedly, this study helped explain BDE209 metabolism in fish and the environmental behavior of BDE209 in other animals. However, further study would be needed to verify 
the transformation between OH-BDEs and MeO-BDEs, and other metabolic pathways of BDEs through in vivo or in vitro approaches.

\section{Conflict of Interest}

The authors have nothing to disclose.

\section{Acknowledgments}

This study was financially supported by the National Natural Science Foundation of China (No. 51290283), National High-Tech R\&D Program (No. 2012AA06A302), and the National Natural Science Foundation of China (No. 41130743).

\section{REFERE N C E S}

Athanasiadou, M., Cuadra, S.N., Marsh, G., Bergman, A., Jakobsson, K., 2008. Polybrominated diphenyl ethers (PBDEs) and bioaccumulative hydroxylated PBDE metabolites in young humans from Managua. Nicaragua. Environ. Health Persp. 116, 400-408.

Buratovic, S., Viberg, H., Fredriksson, A., Eriksson, P., 2014 Developmental exposure to the polybrominated diphenyl ether PBDE 209 neurobehavioural and neuroprotein analysis in adult male and female mice. Environ. Toxicol. Pharm. 38, 570-585

Chen, L., Lebetkin, E., Sanders, J., Burka, L., 2006. Metabolism and disposition of 2, 2',4,4',5-pentabromodiphenyl ether (BDE99) following a single or repeated administration to rats or mice. Xenobiotica 36, 515-534.

Costa, L.G., de Laat, R., Tagliaferri, S., Pellacani, C., 2014. A mechanistic view of polybrominated diphenyl ether (PBDE) developmental neurotoxicity. Toxicol. Lett. 230, 282-294.

Crosse, J.D., Shore, R.F., Jones, K.C., Pereira, M.G., 2012. Long term trends in PBDE concentrations in gannet (Morus bassanus) eggs from two UK colonies. Environ. Pollut. 161, 93-100.

Darnerud, P., Eriksen, G., Johannesson, T., Larsen, P., Viluksela, M., 2001. Polybrominated diphenyl ethers: occurrence, dietary exposure, and toxicology. Environ. Health Persp. 109, 49-68.

de Wit, C., 2002. An overview of brominated flame retardants in the environment. Chemosphere 46, 583-624.

Dingemans, M.M., de Groot, A., van Kleef, R.G., Bergman, Å., van den Berg, M., Vijverberg, H.P., Westerink, R.H., 2008.

Hydroxylation increases the neurotoxic potential of BDE-47 to affect exocytosis and calcium homeostasis in PC12 cells. Environ. Health Persp. 116, 637-643.

Dingemans, M.M., van den Berg, M., Westerink, R.H., 2011. Neurotoxicity of brominated flame retardants: (in) direct effects of parent and hydroxylated polybrominated diphenyl ethers on the (developing) nervous system. Environ. Health Persp. 119, 900-907.

Feng, C., Xu, Y., He, Y., Luo, Q., Zha, J., Wang, Z., 2010. Debrominated and methoxylated polybrominated diphenyl ether metabolites in rainbow trout (Oncorhynchus mykiss) after exposure to decabromodiphenyl ether. J. Environ.Sci. 22, 1425-1434.

Guroff, G., Renson, J., Udenfriend, S., Daly, J.W., Jerina, D.M., Witkop, B., 1967. Hydroxylation-induced migration: The NIH shift recent experiments reveal an unexpected and general result of enzymatic hydroxylation of aromatic compounds. Science 157, 1524-1530.
Guyot, R., Chatonnet, F., Gillet, B., Hughes, S., Flamant, F., 2014. Toxicogenomic analysis of the ability of brominated flame retardants TBBPA and BDE-209 to disrupt thyroid hormone signaling in neural cells. Toxicology 325 , 125-132.

Hamers, T., Kamstra, J.H., Sonneveld, E., Murk, A.J., Visser, T.J. Van Velzen, M.J., Brouwer, A., Bergman, Å., 2008. Biotransformation of brominated flame retardants into potentially endocrine-disrupting metabolites, with special attention to 2, 2', 4, 4'-tetrabromodiphenyl ether (BDE-47). Mol. Nutrit. Food Res. 52, 284-298.

Handayani, D., Edrada, R., Proksch, P., Wray, V., Witte, L., Van Soest, R., Kunzmann, A., 1997. Four new bioactive polybrominated diphenyl ethers of the sponge Dysidea herbacea from West Sumatra. Indonesia. J. Nat. Prod. 60, 1313-1316.

Harju, M., Hamers, T., Kamstra, J.H., Sonneveld, E., Boon, J.P., Tysklind, M., Andersson, P.L., 2007. Quantitative structure-activity relationship modeling on in vitro endocrine effects and metabolic stability involving 26 selected brominated flame retardants. Environ. Toxicol. Chem. 26, 816-826.

Hooper, K., McDonald, T., 2000. The PBDEs: an emerging environmental challenge and another reason for breast-milk monitoring programs. Environ. Health Persp. 108, 387-392.

Jerina, D., Daly, J., 1974. Arene oxides: a new aspect of drug metabolism. Science 185, 573

Kierkegaard, A., Balk, L., Tjarnlund, U., De Wit, C., Jansson, B., 1999. Dietary uptake and biological effects of decabromodiphenyl ether in rainbow trout (Oncorhynchus mykiss). Environ. Sci. Technol. 33, 1612-1617.

Kelly, B.C., Ikonomou, M.G., Blair, J.D., Gobas, F.A.P.C., 2008. Hydroxylated and methoxylated polybrominated diphenyl ethers in a Canadian Arctic marine food web. Environ. Sci. Technol. 42, 7069-7077.

Li, F., Xie, Q., Li, X., Li, N., Chi, P., Chen, J., Wang, Z., Hao, C., 2010. Hormone activity of hydroxylated polybrominated diphenyl ethers on human thyroid receptor- $\beta$ : in vitro and in silico investigations. Environ. Health Persp. 118, 602-606.

Malmberg, T., Athanasiadou, M., Marsh, G., Brandt, I., Bergman, A., 2005. Identification of hydroxylated polybrominated diphenyl ether metabolites in blood plasma from polybrominated diphenyl ether exposed rats. Environ. Sci.Technol. 39, 5342-5348.

Malmvärn, A., Marsh, G., Kautsky, L., Athanasiadou, M., Bergman, A., Asplund, L., 2005. Hydroxylated and methoxylated brominated diphenyl ethers in the red algae ceramium tenuicorne and blue mussels from the Baltic Sea. Environ. Sci. Technol. 39, 2990-2997.

Malmvärn, A., Zebuhr, Y., Kautsky, L., Bergman, A., Asplund, L., 2008. Hydroxylated and methoxylated polybrominated diphenyl ethers and polybrominated dibenzo-p-dioxins in red alga and cyanobacteria living in the Baltic Sea. Chemosphere 72, 910-916.

Marsh, G., Athanasiadou, M., Athanassiadis, I., Sandholm, A., 2006. Identification of hydroxylated metabolites in 2,2',4,4'-tetrabromodiphenyl ether exposed rats. Chemosphere 63, 690-697.

Marsh, G., Athanasiadou, M., Bergman, A., Asplund, L., 2004 Identification of hydroxylated and methoxylated polybrominated diphenyl ethers in Baltic Sea salmon (Salmo salar) blood. Environ. Sci. Technol. 38, 10-18.

Meerts, I., Letche, r.R., Hoving, S., Marsh, G., Bergman, A., Lemmen, J., Van der Burg, B., Brouwer, A., 2001. In vitro estrogenicity of polybrominated diphenyl ethers, hydroxylated PDBEs, and polybrominated bisphenol A compounds. Environ. Health Persp. 109, 399-407. 
Montory, M., Barra, R., 2006. Preliminary data on polybrominated diphenyl ethers (PBDEs) in farmed fish tissues (Salmo salar) and fish feed in Southern Chile. Chemosphere 63, 1252-1260.

Mörck, A., Hakk, H., Orn, U., Wehler, E., 2003. Decabromodiphenyl ether in the rat: absorption, distribution, metabolism, and excretion. Drug Metab. Dispos. 31, 900-907.

Nelson, C., Drouillard, K., Cheng, K., Elliott, J., Ismail, N., 2015. Accumulation of PBDEs in an urban river otter population and an unusual finding of BDE-209. Chemosphere 118, 322-328.

Qiu, X., Mercado-Feliciano, M., Bigsby, R., Hites, R., 2007. Measurement of polybrominated diphenyl ethers and metabolites in mouse plasma after exposure to a commercial pentabromodiphenyl ether mixture. Environ. Health Persp. 115, 1052-1058.

Roberts, S.C., Noyes, P.D., Gallagher, E.P., Stapleton, H.M., 2011. Species-specific differences and structure - activity relationships in the debromination of PBDE congeners in three fish species. Environ. Sci. Technol. 45, 1999-2005.

Stapleton, H., Alaee, M., Letcher, R., Baker, J., 2004a. Debromination of the flame retardant decabromodiphenyl ether by juvenile carp (Cyprinus carpio) following dietary exposure. Environ. Sci. Technol. 38, 112-119.

Stapleton, H., Brazil, B., Holbrook, R., Mitchelmore, C., Benedict, R., Konstantinov, A., Potter, D., 2006. In vivo and in vitro debromination of decabromodiphenyl ether (BDE 209) by juvenile rainbow trout and common carp. Environ. Sci. Technol. 40, 4653-4658.

Stapleton, H., Kelly, S., Pei, R., Letcher, R., Gunsch, C., 2009. Metabolism of polybrominated diphenyl ethers (PBDEs) by human hepatocytes in vitro. Environ. Health Persp. 117, 197-202.

Stapleton, H., Letcher, R., Li, J., Baker, J., 2004b. Dietary accumulation and metabolism of polybrominated diphenyl ethers by juvenile carp (Cyprinus carpio). Environ. Toxicol. Chem. 23, 1939-1946.

Sun, J., Liu, J., Liu, Y., Jiang, G., 2013. Hydroxylated and methoxylated polybrominated diphenyl ethers in mollusks from Chinese coastal areas. Chemosphere 92, 322-328.

Szabo, D.T., Diliberto, J.J., Hakk, H., Huwe, J.K., Birnbaum, L.S., 2010. Toxicokinetics of the flame retardant hexabromocyclododecane gamma: effect of dose, timing, route, repeated exposure, and metabolism. Toxicol. Sci. 117, 282-293.

Teuten, E., Xu, L., Reddy, C., 2005. Two abundant bioaccumulated halogenated compounds are natural products. Am. Assoc. Advancement Sci., 917-920.
Valters, K., Li, H., Alaee, M., D’Sa, I., Marsh, G., Bergman, A., Letcher, R., 2005. Polybrominated diphenyl ethers and hydroxylated and methoxylated brominated and chlorinated analogues in the plasma of fish from the Detroit River. Environ. Sci. Technol. 39, 5612-5619.

Van den Steen, E., Covaci, A., Jaspers, V.L., Dauwe, T., Voorspoels, S., Eens, M., Pinxten, R., 2007. Accumulation, tissue-specific distribution and debromination of decabromodiphenyl ether (BDE 209) in European starlings (Sturnus vulgaris). Environ. Pollut. 148, 648-653.

Verreault, J., Gabrielsen, G., Chu, S., Muir, D., Andersen, M., Hamaed, A., Letchers, R., 2005. Flame retardants and methoxylated and hydroxylated polybrominated diphenyl ethers in two Norwegian Arctic top predators: glaucous gulls and polar bears. Environ. Sci. Technol. 39, 6021-6028.

Wan, Y., Liu, F., Wiseman, S., Zhang, X., Chang, H., Hecker, M., Jones, P.D., Lam, M.H., Giesy, J.P., 2010. Interconversion of hydroxylated and methoxylated polybrominated diphenyl ethers in Japanese medaka. Environ. Sci. Technol. 44, 8729-8735.

Wan, Y., Wiseman, S., Chang, H., Zhang, X., Jones, P., Hecker, M., Kannan, K., Tanabe, S., Hu, J., Lam, M., 2009. Origin of hydroxylated brominated diphenyl ethers: natural compounds or man-made flame retardants? Environ. Sci. Technol. 43, 7536-7542.

Wang, S., Zhang, S., Huang, H., Lu, A., Ping, H., 2012. Debrominated, hydroxylated and methoxylated metabolism in maize (Zea mays L.) exposed to lesser polybrominated diphenyl ethers (PBDEs). Chemosphere 89, 1295-1301.

Wang, S., Zhang, S., Huang, H., Niu, Z., Han, W., 2014. Characterization of polybrominated diphenyl ethers (PBDEs) and hydroxylated and methoxylated PBDEs in soils and plants from an e-waste area. China Environ. Pollut. 184, 405-413.

Wen, Q., Liu, H., Zhu, Y., Zheng, X., Su, G., Zhang, X., Yu, H., Giesy, J.P., Lam, M.H.W., 2015. Maternal transfer, distribution, and metabolism of BDE-47 and its related hydroxylated, methoxylated analogs in zebrafish (Danio rerio). Chemosphere 120, 31-36.

Wiseman, S.B., Wan, Y., Chang, H., Zhang, X., Hecker, M., Jones, P.D., Giesy, J.P., 2011. Polybrominated diphenyl ethers and their hydroxylated/methoxylated analogs: environmental sources, metabolic relationships, and relative toxicities. Mar. Pollut. Bull. 63, 179-188.

Xie, Z., Lu, G., Qi, P., 2014. Effects of BDE-209 and its mixtures with BDE-47 and BDE-99 on multiple biomarkers in Carassius auratus. Environ. Toxicol. Pharm. 38, 554-561. 